\title{
Multicenter survey of symptoms, work life, economic status, and quality of life of complex regional pain syndrome patients
}

\author{
Jaemoon Lee ${ }^{1}$, Yun Hee Lim², Sung Jun Hong ${ }^{3}$, Jae Hun Jeong ${ }^{4}$, Hey Ran Choi ${ }^{5}$, Sun Kyung Park ${ }^{6}$, \\ Jung Eun Kim ${ }^{7}$, Eun Hi Park ${ }^{1}$, and Jae Hun Kim ${ }^{1}$ \\ 'Department of Anesthesiology and Pain Medicine, Konkuk University School of Medicine, Seoul, Korea \\ ${ }^{2}$ Department of Anesthesiology and Pain Medicine, Inje University Sanggye Paik Hospital, Seoul, Korea \\ ${ }^{3}$ Department of Anesthesiology and Pain Medicine, Hallym University Kangdong Sacred Heart Hospital, Seoul, Korea \\ ${ }^{4}$ Department of Anesthesiology and Pain Medicine, Jeong-clinic, Seoul, Korea \\ ${ }^{5}$ Department of Anesthesiology and Pain Medicine, Inje University Seoul Paik Hospital, Seoul, Korea \\ ${ }^{6}$ Department of Anesthesiology and Pain Medicine, Jeju National University School of Medicine, Jeju, Korea \\ ${ }^{7}$ Department of Anesthesiology and Pain Medicine, Hallym University Kangnam Sacred Heart Hospital, Seoul, Korea
}

Received December 24, 2020

Revised March 10, 2021

Accepted March 23, 2021

Handling Editor: Jeong-Gill Leem

\section{Correspondence}

Jae Hun Kim

Department of Anesthesiology and Pain Medicine, Konkuk University Medical

Center, Konkuk University School

of Medicine, 120-1 Neungdong-ro,

Gwangjin-gu, Seoul 05030, Korea

Tel: +82-2-2030-5749

Fax: $+82-2-2030-5449$

E-mail: painfree@kuh.ac.kr
Background: Complex regional pain syndrome (CRPS) is an intractable pain disease with various symptoms. Here, we investigated the disease status, work life, sleep problems, medical insurance, economic status, psychological problems, and quality of life (QOL) of CRPS patients.

Methods: CRPS patients from 37 university hospitals in South Korea were surveyed. The survey questionnaire consisted of 24 questions on the following aspects of CRPS patients: sex, age, occupation, cause of injury, activities of daily living (ADL), pain severity, sleep disturbance, level of education, economic status, therapeutic effect, and suicidal ideation. Additionally, the abbreviated World Health Organization Quality of Life (WHOQOL-BREF) questionnaire, consisting of 26 questions, was used to identify the status of QOL.

Results: A total of 251 patients completed the questionnaire. According to the survey, 54.2\% patients could not perform ADL on their own. Over the previous week, the mean pain score was $7.15 \pm 1.78$ (out of a total of 10 points); $92.1 \%$ of patients had sleep disorders and $80.5 \%$ had suicidal ideation, with most patients suffering from psychological problems. The average for each domain of WHOQOL-BREF was as follows: $21.74 \pm 14.77$ for physical, $25.22 \pm 17.66$ for psychological, $32.02 \pm$ 22.36 for social relationship, and $30.69 \pm 15.83$ for environmental (out of a total of 100 points each). Occupation, ADL, sleep time, therapeutic effect, and suicidal ideation were statistically correlated with multiple domains.

Conclusions: Most patients had moderate to severe pain, economic problems, limitations of their ADL, sleep problems, psychological problems, and a low QOL score.

Key Words: Activities of Daily Living; Chronic Pain; Complex Regional Pain Syndromes; Economic Status; Educational Status; Occupations; Pain, Intractable; Quality of Life; Sleep Wake Disorders; Suicidal Ideation; Surveys and Questionnaires. (c) This is an open-access article distributed under the terms of the Creative Commons Attribution Non-Commercial License (http://creativecommons.org/licenses/by-nc/4.0/), which permits unrestricted non-commercial use, distribution, and reproduction in any medium, provided the original work is properly cited.

(c) The Korean Pain Society, 2021
Author contributions: Jaemoon Lee: Writing/manuscript preparation; Yun Hee Lim: Study conception; Sung Jun Hong: Study conception; Jae Hun Jeong: Study conception; Hey Ran Choi: Study conception; Sun Kyung Park: Study conception; Jung Eun Kim: Study conception; Eun Hi Park: Study conception; Jae Hun Kim: Supervision. 


\section{INTRODUCTION}

Complex regional pain syndrome (CRPS) is a rare and intractable disease with various major symptoms of pain [1]. It is an inflammatory and neuropathic pain disorder principally characterized by involvement of the autonomic nervous system $[2,3]$. The etiology of the syndrome is not clear and the known treatment modality is also very difficult [2-4].

A recent study using the current International Association for the Study of Pain (IASP) diagnostic criteria reported an incidence as high as 25.2 new cases per 100,000 annually [5]. The number of patients in South Korea is not clear, but the annual incidence rate is around 29 per 100,000 people, according to the data analysis of the Korean Health Insurance Review \& Assessment Service in 2015. More than 1,000 new patients are reported every year in South Korea [6].

Chronic pain is a part of the International Classification of Diseases (ICD-11) and has a major influence on the quality of life (QOL) [7]. However, CRPS, which is the highest-scoring disease on the McGill pain scale, is still unknown to the public [8]. Since the pathogenesis of CRPS is yet to be clarified, doctors and researchers have not fully understood the disease $[9,10]$. This makes it difficult to diagnose and treat the disease. The patients also face difficulties in conducting their daily life activities. This often leads to misunderstandings about the true nature of the pain that the patients are experiencing, thereby making it difficult for the patients to deal with the disease.

Pain is likely to accompany psychological disorders such as insomnia and anxiety, and this is also thought to affect the QOL of patients [11]. In addition, patients are often accompanied by a variety of economic and mental distresses as well as long-term severe pain, which leads to limitations in their functioning in daily life [12]. However, some people still misunderstand the reality of the pain, which makes it more difficult for the patient. In this study, we investigated the disease status, work life, sleep problems, medical insurance, economic status, psychological problems, and QOL of CRPS patients.

\section{MATERIALS AND METHODS}

The ethical approval for this study was waived by the In-

Table 1. Demographic data 1

\begin{tabular}{|c|c|c|}
\hline Demographic variable & Categories & Number of patients (\%) \\
\hline \multirow[t]{2}{*}{ Sex } & Male & $160(63.8)$ \\
\hline & Female & $91(36.2)$ \\
\hline Age & $\leq 20 \mathrm{yr}$ & $1(0.4)$ \\
\hline \multirow[t]{5}{*}{ Total $n=251$, excluding 1 non-respondents } & $21-30 \mathrm{yr}$ & $35(14.0)$ \\
\hline & $31-40 \mathrm{yr}$ & $51(20.4)$ \\
\hline & $41-50 \mathrm{yr}$ & $77(30.8)$ \\
\hline & $51-60 \mathrm{yr}$ & $57(22.8)$ \\
\hline & $>60 \mathrm{yr}$ & $29(11.6)$ \\
\hline Treatment period & Less than $1 \mathrm{yr}$ & $37(14.9)$ \\
\hline \multirow[t]{4}{*}{ Total $n=251$, excluding 3 non-respondents } & 1 or more-less than 3 yrs & $69(27.8)$ \\
\hline & 3 or more-less than 5 yrs & $50(20.2)$ \\
\hline & 5 or more-less than $10 \mathrm{yrs}$ & $63(25.4)$ \\
\hline & 10 yrs or more & $29(11.7)$ \\
\hline Cause of injury & Traffic accidents & $75(30.5)$ \\
\hline \multirow[t]{3}{*}{ Total $n=251$, excluding 5 non-respondents } & Industrial accidents & $75(30.5)$ \\
\hline & Others & 77 (31.3) \\
\hline & Unknown & $19(7.7)$ \\
\hline Pain site (origin) & Rt. upper extremity & $46(18.5)$ \\
\hline \multirow[t]{4}{*}{ Total $n=251$, excluding 3 non-respondents } & Lt. upper extremity & $50(20.2)$ \\
\hline & Rt. lower extremity & $76(30.7)$ \\
\hline & Lt. lower extremity & $65(26.2)$ \\
\hline & Others & $11(4.4)$ \\
\hline Pain site (current) & One extremity & $133(54.5)$ \\
\hline \multirow[t]{4}{*}{ Total $n=251$, excluding 7 non-respondents } & Two extremities & $42(17.2)$ \\
\hline & Three extremities & $20(8.2)$ \\
\hline & Whole extremities & $42(17.2)$ \\
\hline & Others & $7(2.9)$ \\
\hline
\end{tabular}

Rt.: right, Lt.: left. 


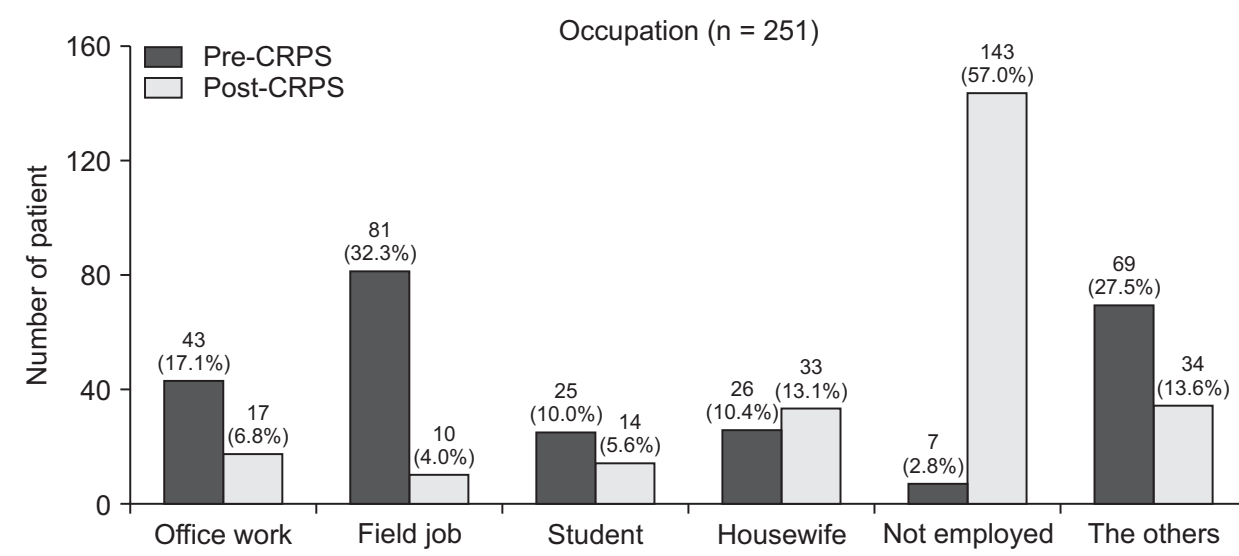

Fig. 1. Representation of data for occupational changes in patients before and after complex regional pain syndrome (CRPS) outbreak.
Period (diagnosis, $\mathrm{n}=248$ )

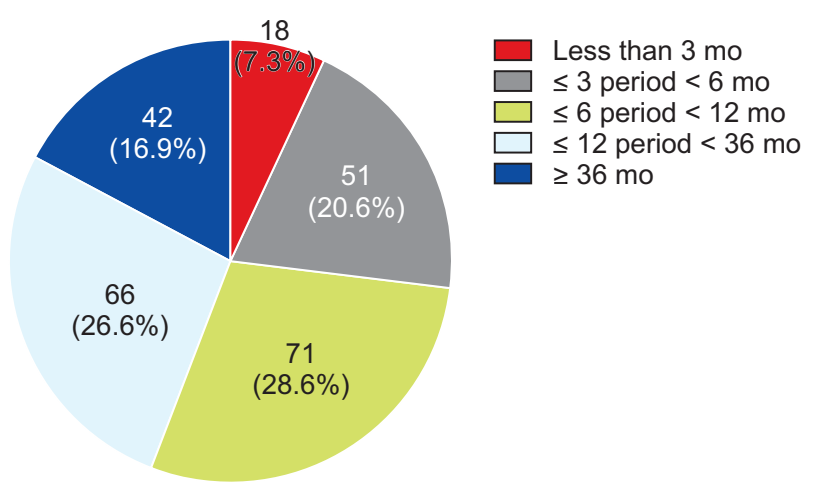

Fig. 2. Representation of data for time span for diagnosis of complex regional pain syndrome.

stitutional Review Board of Konkuk University Hospital (IRB no. KUMC 2020-03-001). The survey was conducted by the Publicity Committee of the Korean Pain Society from July 1 to August 31, 2019. Based on the results of this anonymous survey, this manuscript was drafted in 2020.

This was a cross-sectional study conducted on CRPS patients who visited pain clinics at 37 university hospitals in Korea. The inclusion criterion was diagnosis of a patient with CRPS using the IASP CRPS diagnostic criteria [13]. The survey was conducted only for patients who agreed to participate in the survey. Patients who did not agree to participate in the survey were excluded.

The questionnaire (Appendix) consists of 50 questions focusing on the following aspects of the participants: sex, age, occupation, cause of damage, disease-affected areas, time before diagnosis, degree of pain, and sleep time. The patient's knowledge about the disease was also checked in terms of whether the patient was aware of the pathogenesis of the disease, the diagnostic criteria, or the treatment methods. The patients could select the source of information from multiple options. The abbreviated World Health Organization Quality of Life (WHOQOL-BREF) consisting of 26 questions was used to identify the status of QOL.

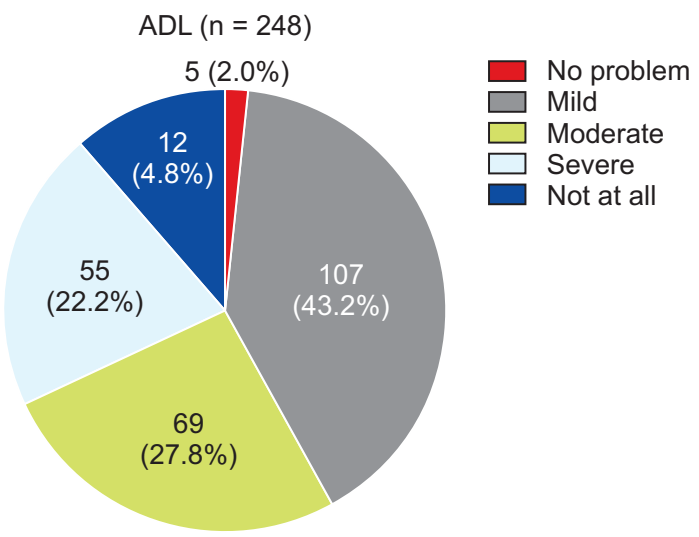

Fig. 3. Representation of data for the degree of activity of daily living (ADL) of complex regional pain syndrome patients.

The data were analyzed with SPSS version 17 (SPSS Inc., Chicago, IL), using the chi-squared test, Student's t-test, and multiple linear regression analysis. The proportional differences were evaluated using the chi-squared test. The mean differences were analyzed using Student's $t$-test. To evaluate the factors that affected the satisfaction level of the patient with treatment and the performance of posttreatment management, the respondents were divided into two groups, the satisfaction group and the dissatisfaction group. In terms of treatment, patients were divided into the performance group and the non-performance group in post-treatment management (in these groups, the patients who answered neutrally were excluded). To analyze the relationship between WHOQOL-BREF and the patients' factors (sex, age, current job status, period from the onset of pain to diagnosis), multiple-linear regression analysis was used. Before multiple linear regression analysis, using the chi-squared test and Student's $t$-test, we found the factors having $P<0.1$ were related to the WHOQOL-BREF. These factors were then analyzed by multiple linear regression analysis. Statistical significance was set at $P<0.05$. 


\section{RESULTS}

A total of 251 patients from 37 hospitals completed the questionnaire. The questionnaire was comprised of questions corresponding to the WHOQOL-BREF as well as questions about the patient's demographic data and current situation. Table $\mathbf{1}$ describes aspects covered by all questions except the WHOQOL-BREF questions, namely the patient's sex, age, period (therapy), cause of injury, and pain site. The current rate of unemployment among the surveyed patients was $57.0 \%$ (143 patients), a sharp increase from $2.8 \%$ ( 7 patients) before the onset of the disease (Fig. 1). In addition, $43.5 \%$ (108 patients out of a total of 251 patients, excluding 3 non-respondents) were diagnosed with CRPS after more than one year from onset of pain (Fig. 2). Among the participants, $54.8 \%$ were unable

Table 2. Demographic data 2

\begin{tabular}{|c|c|c|}
\hline Demographic variable & Categories & Number of patients (\%) \\
\hline \multirow[t]{3}{*}{ Pain severity (1 week) } & Mild & $9(3.6)$ \\
\hline & Moderate & $72(28.7)$ \\
\hline & Severe & $170(67.7)$ \\
\hline \multirow[t]{3}{*}{ Pain severity (current) } & Mild & $10(4.0)$ \\
\hline & Moderate & $94(37.4)$ \\
\hline & Severe & $147(58.6)$ \\
\hline Sleep disturbance & Pain & $223(92.2)$ \\
\hline Total $n=251$, excluding 9 non-respondents & Etc. & $19(7.8)$ \\
\hline Knowledge (pathophysiology) & Well known & $63(25.3)$ \\
\hline \multirow[t]{2}{*}{ Total $n=251$, excluding 2 non-respondents } & Known & $140(56.2)$ \\
\hline & Not known & 46 (18.5) \\
\hline \multirow[t]{3}{*}{ Knowledge (diagnosis) } & Well known & $62(24.7)$ \\
\hline & Known & $114(45.4)$ \\
\hline & Not known & $75(29.9)$ \\
\hline \multirow[t]{3}{*}{ Knowledge (therapy) } & Well known & $72(28.7)$ \\
\hline & Known & $125(49.8)$ \\
\hline & Not known & $54(21.5)$ \\
\hline Knowledge (acquiring route) & Dr. and nurse & $203(81.9)$ \\
\hline \multirow[t]{3}{*}{ Total $n=251$, excluding 3 non-respondents } & Newspaper & $30(12.1)$ \\
\hline & Peer group & $7(2.8)$ \\
\hline & The others & $8(3.2)$ \\
\hline Payment (medical) & Medical insurance & $111(44.7)$ \\
\hline \multirow[t]{3}{*}{ Total $n=251$, excluding 3 non-respondents } & Social insurance & 30 (12.1) \\
\hline & Industrial insurance & $53(21.4)$ \\
\hline & Car insurance & $54(21.8)$ \\
\hline Monthly income (W) & Income $<500,000$ & $49(39.2)$ \\
\hline \multirow[t]{4}{*}{ Total $n=251$, excluding 126 non-respondents } & $500,000 \leq$ income $<1,000,000$ & $12(9.6)$ \\
\hline & $1,000,000 \leq$ income $<2,000,000$ & $30(24.0)$ \\
\hline & $2,000,000 \leq$ income $<3,000,000$ & $21(16.8)$ \\
\hline & $3,000,000 \leq$ income & $13(10.4)$ \\
\hline Source of money & Family & 117 (52.9) \\
\hline \multirow[t]{5}{*}{ Total $n=251$, excluding 30 non-respondents } & Loan & $17(7.7)$ \\
\hline & Deposit & $22(10.0)$ \\
\hline & Insurance & $38(17.2)$ \\
\hline & Social insurance & $18(8.1)$ \\
\hline & The others & $9(4.1)$ \\
\hline Effect of therapy & $>75 \%$ & $9(3.7)$ \\
\hline \multirow[t]{4}{*}{ Total $n=251$, excluding 6 non-respondents } & $50-75 \%$ & $26(10.6)$ \\
\hline & $25-49 \%$ & $58(23.6)$ \\
\hline & $<25 \%$ & $82(33.5)$ \\
\hline & Not at all & $70(28.6)$ \\
\hline Use of drugs & Psychiatrics & $25(10.3)$ \\
\hline \multirow[t]{3}{*}{ Total $n=251$, excluding 7 non-respondents } & Opioid & $62(25.4)$ \\
\hline & Both & $134(54.9)$ \\
\hline & Neither & $23(9.4)$ \\
\hline
\end{tabular}


to perform activities of daily living (ADL) on their own (136 patients out of 251 patients, excluding 3 non-respondents) (Fig. 3).

Table 2 describes data regarding pain severity (1 week history and current), knowledge (pathophysiology, diagnosis, therapy, route of acquisition), payment (medical), income, source of money, effect of therapy, and use of drugs. Over the previous week, pain scores were: 0-3 in 9 patients (3.6\%), 4-6 in 72 patients (28.7\%), and 7-10 in 170 patients (67.7\%). The mean score was $7.15 \pm 1.78$ over the previous week (out of a total of 10 points). At the time of survey, pain scores were: $0-3$ in 10 patients (4.0\%), 4-6 in 94 patients (37.4\%), and 7-10 in 147 patients (58.6\%).

Patients slept for $4.92 \pm 2.28$ hours on average. Paininduced sleep disorders were reported by $92.1 \%$ of patients (223 patients out of 251 patients, excluding 9 nonrespondents) (Fig. 4). Further, 83.4\% of patients mentioned that they had economic difficulties (206 patients out of a total 251 patients, excluding 4 non-respondents) while $84.6 \%$ were unable to engage in economic activities $(208$

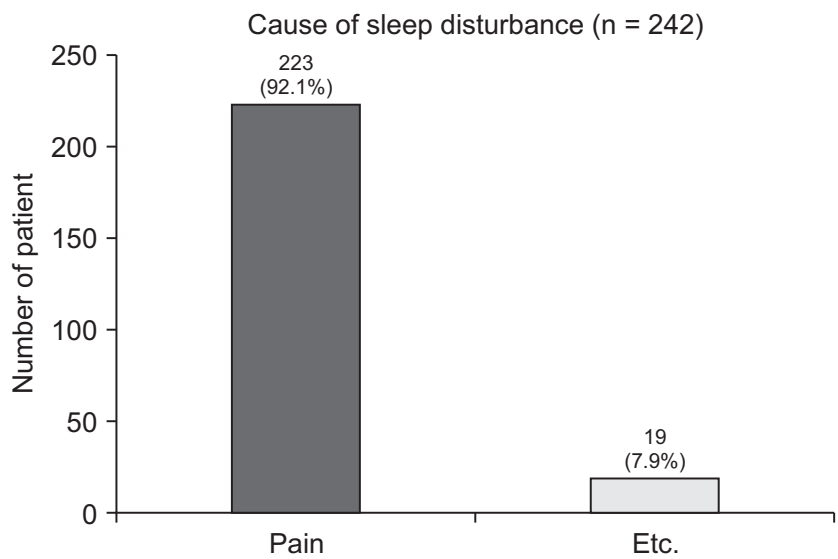

Fig. 4. Representation of data for prevalence of sleep disturbance caused by pain in complex regional pain syndrome patients.

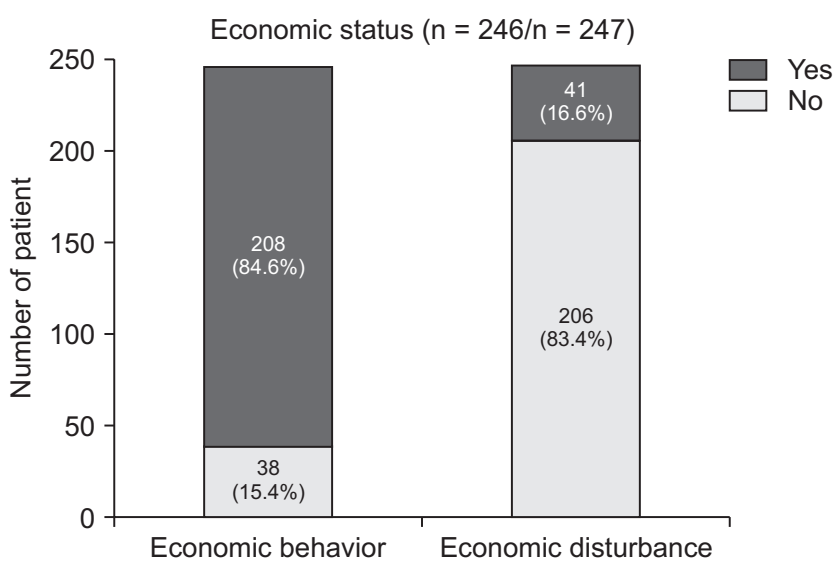

Fig. 5. Representation of data for impact of complex regional pain syndrome on economic activities and economic difficulties among patients. out of a total 251 patients, excluding 5 non-respondents) (Fig. 5). Surprisingly, only $14.3 \%$ of patients (35 of a total of 251 patients, excluding 6 non-respondents) had more than $50 \%$ pain relief. Twenty-five patients $(10.3 \%)$ had been consuming psychotropic medication, while 62 patients $(25.4 \%)$ were consuming opioids. A total of 134 patients (54.9\%) were consuming both types of medication, while 23 patients $(9.4 \%)$ were consuming neither. The percentage of patients who had experienced suicidal ideation was $80.5 \%$ (198 of a total of 251 patients, excluding 5 non-respondents) (Fig. 6).

Table 3 describes the mean and standard deviation for the average values for questions in the survey, with pain scores, sleep duration, and scores for each domain. The average pain score for the past week was $7.15 \pm 1.78$ (out of a total of 10 points), and the average sleep duration was 4.92 \pm 2.28 hours. Additionally, the average value and standard

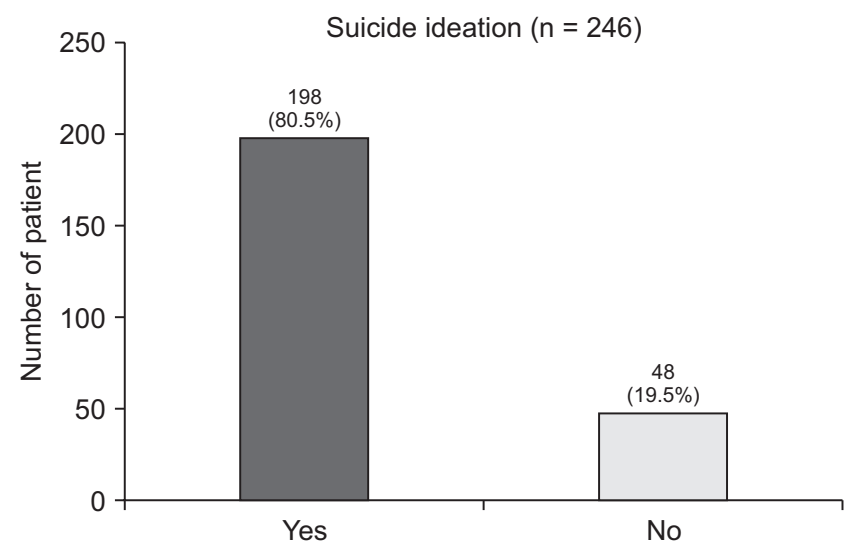

Fig. 6. Representation of data for prevalence of suicidal ideation in complex regional pain syndrome patients.

Table 3. Average and standard deviation of patient's status and WHOQOL-BREF domains

\begin{tabular}{lccrc}
\hline \multicolumn{1}{c}{ Domain } & Minimum & Maximum & Average & $\begin{array}{c}\text { Standard } \\
\text { deviation }\end{array}$ \\
\hline Pain severity (last week) & 1 & 10 & 7.15 & 1.78 \\
Sleep duration & 0 & 17 & 4.92 & 2.28 \\
BREF-Q1 & 1 & 4 & 1.77 & 0.76 \\
BREF-Q2 & 1 & 5 & 1.58 & 0.69 \\
Physical health 20 & 4 & 14 & 7.46 & 2.36 \\
Physical health 100 & 0 & 63 & 21.74 & 14.77 \\
Psychological 20 & 4 & 16 & 8.03 & 2.82 \\
Psychological 100 & 0 & 75 & 25.22 & 17.66 \\
Social relationships 20 & 4 & 19 & 9.12 & 3.57 \\
Social relationships 100 & 0 & 94 & 32.02 & 22.35 \\
Environment 20 & 4 & 18 & 8.87 & 2.52 \\
Environment 100 & 0 & 88 & 30.69 & 15.83 \\
\hline
\end{tabular}

WHOQOL-BREF: abbreviated World Health Organization Quality of Life, BREF-Q1: Basic Satisfaction Question 1 on WHOQOL-BREF, BREF-Q2: Basic Satisfaction Question 2 on WHOQOL-BREF. 
Table 4. Correlation analysis between patient's status and QOL $(n=251)$

\begin{tabular}{lccrrrr}
\hline \multicolumn{1}{c}{ Variable } & BREF-Q1 & BREF-Q2 & Physical & Psychological & Social & Environment \\
\hline Sex & 0.973 & 0.523 & 0.110 & 0.031 & 0.095 & 0.505 \\
Age & 0.005 & 0.074 & 0.009 & 0.001 & 0.006 & $<0.001$ \\
Job status (current) & 0.005 & 0.006 & $<0.001$ & 0.002 & 0.065 & 0.001 \\
Period (diagnosis) & 0.972 & 0.042 & 0.810 & 0.386 & 0.146 & 0.121 \\
Pain site (current) & 0.059 & 0.005 & 0.078 & 0.359 & 0.105 & 0.048 \\
Current ADL & $<0.001$ & $<0.001$ & $<0.001$ & $<0.001$ & $<0.001$ & $<0.001$ \\
Pain severity (last week) & $<0.001$ & $<0.001$ & $<0.001$ & $<0.001$ & $<0.001$ & $<0.001$ \\
Sleep duration & $<0.001$ & $<0.001$ & $<0.001$ & $<0.001$ & $<0.001$ & $<.005$ \\
Effect of therapy & $<0.001$ & $<0.001$ & $<0.001$ & 0.001 & $<0.001$ \\
Suicidal ideation & $<0.001$ & $<0.001$ & $<0.001$ & $<0.001$ & $<0.001$ & 0.001 \\
\hline
\end{tabular}

QOL: quality of life, WHOQOL-BREF: abbreviated World Health Organization Quality of Life, BREF-Q1: Basic Satisfaction Question 1 on WHOQOL-BREF, BREF-Q2: Basic Satisfaction Question 2 on WHOQOL-BREF, Perioid (diagnosis): duration from the onset of pain to diagnosis, ADL: activities of daily living.

Table 5. Multiple linear regression analysis for BREF-Q1 $(n=251)$

\begin{tabular}{|c|c|c|c|c|c|}
\hline \multirow{2}{*}{ Variable } & \multicolumn{5}{|c|}{ BREF-Q1 } \\
\hline & $B$ & SE B & $\beta$ & $t$ & $P$ value \\
\hline Age & -0.056 & 0.037 & -0.087 & -1.521 & 0.130 \\
\hline Job status (current) & 0.202 & 0.097 & 0.118 & 2.076 & 0.039 \\
\hline Pain site (current) & -0.006 & 0.037 & -0.009 & -0.167 & 0.867 \\
\hline Current ADL & -0.119 & 0.050 & -0.145 & -2.400 & 0.017 \\
\hline Pain severity (last week) & -0.063 & 0.029 & -0.144 & -2.130 & 0.034 \\
\hline Sleep duration & 0.028 & 0.020 & 0.082 & 1.443 & 0.150 \\
\hline Effect of therapy & -0.183 & 0.043 & -0.262 & -4.263 & $<0.001$ \\
\hline Suicidal ideation & 0.396 & 0.112 & 0.204 & 3.538 & $<0.001$ \\
\hline
\end{tabular}

WHOQOL-BREF: abbreviated World Health Organization Quality of Life, BREF-Q1: Basic Satisfaction Question 1 on WHOQOL-BREF, ADL: activities of daily living, SE: standard error.

deviation of each domain in the WHOQOL-BREF survey are shown (two basic satisfaction surveys, physical, psychological, social, and environmental). Table 4 shows the correlation between each domain and the patient's condition with a $P$ value $<0.1$ (using the chi-squared test and Student's $t$-test).

Table 5 shows the multiple linear regression between BREF-Q1 (Basic Satisfaction Question 1 on the WHOQOLBREF) and patient status (items in Table $\mathbf{1}$ and Table 2). The correlation between the items in Table 4 and BREFQ1 was a multiple linear regression. Among them, items that were correlated with a $P$ value $<0.05$ were current job status ( $\mathrm{t}=2.076, P=0.039)$, current ADL $(\mathrm{t}=-2.4, P=0.017)$, last week pain severity $(\mathrm{t}=-2.13, P=0.034)$, therapeutic effect $(\mathrm{t}=-4.263, P<0.001)$, and suicidal ideation $(\mathrm{t}=3.538, P$ $<0.001)$.

Table 6 shows the multiple linear regression between WHOQOL-BREF-Q2 (Basic Satisfaction Question 2 on the WHOQOL-BREF) and patient status (items in Table $\mathbf{1}$ and Table 2). The correlation between items in Table 4 and BREF-Q2 was a multiple linear regression. Among them, items that were correlated with a $P$ value $<0.05$ were sleep duration ( $\mathrm{t}=3.018, P=0.003)$, therapeutic effect $(\mathrm{t}=-3.52$, $P=0.001)$, and suicidal ideation $(\mathrm{t}=3.3, P=0.001)$.

Table 7 shows the multiple linear regression between the physical domain and the patient's status (items in Table 1 and Table 2). The correlation between the items in Table $\mathbf{4}$ and the physical domain was a multiple linear regression. Among them, items that were correlated with a $P$ value $<0.05$ were current job status $(\mathrm{t}=2.164, P=0.032)$, current ADL ( $\mathrm{t}=-2.766, P=0.006)$, last week pain severity $(\mathrm{t}=-3.208, P=0.002)$, sleep duration $(\mathrm{t}=2.711, P=0.007)$, therapeutic effect $(\mathrm{t}=-1.966, P=0.049)$, and suicidal ideation $(\mathrm{t}=3.512, P=0.001)$.

Table 8 shows the multiple linear regression between the psychological domain and the patient's status (items in Table 1 and Table 2). The correlation between the items in Table 4 and the psychological domain was a multiple linear regression. Among them, items that were correlated with a $P$ value $<0.05$ were current job status $(\mathrm{t}=2.697, P$ $=0.008)$, sleep duration $(\mathrm{t}=2.137, P=0.034)$, and suicidal ideation $(\mathrm{t}=5.422, P<0.001)$. 
Table 6. Multiple linear regression analysis for BREF-Q2 $(n=251)$

\begin{tabular}{|c|c|c|c|c|c|}
\hline \multirow{2}{*}{ Variable } & \multicolumn{5}{|c|}{ BREF-Q2 } \\
\hline & $B$ & $S E B$ & $\beta$ & $t$ & $P$ value \\
\hline Age & $<0.001$ & 0.035 & $<0.001$ & 0.005 & 0.996 \\
\hline Job status (current) & 0.181 & 0.094 & 0.116 & 1.932 & 0.055 \\
\hline Perioid (diagnosis) & 0.018 & 0.035 & 0.030 & 0.514 & 0.608 \\
\hline Pain site (current) & -0.018 & 0.036 & -0.030 & -0.502 & 0.616 \\
\hline Current ADL & -0.073 & 0.049 & -0.098 & -1.506 & 0.134 \\
\hline Pain severity (last week) & -0.031 & 0.028 & -0.080 & -1.107 & 0.269 \\
\hline Sleep duration & 0.057 & 0.019 & 0.183 & 3.018 & 0.003 \\
\hline Effect of therapy & -0.147 & 0.042 & -0.232 & -3.520 & 0.001 \\
\hline Suicidal impulse & 0.358 & 0.108 & 0.203 & 3.300 & 0.001 \\
\hline
\end{tabular}

WHOQOL-BREF: abbreviated World Health Organization Quality of Life, BREF-Q2: Basic Satisfaction Question 2 on WHOQOL-BREF, Perioid (diagnosis): duration from the onset of pain to diagnosis, ADL: activities of daily living, SE: standard error.

Table 7. Multiple linear regression analysis for physical domain $(n=251)$

\begin{tabular}{|c|c|c|c|c|c|}
\hline \multirow{2}{*}{ Variable } & \multicolumn{5}{|c|}{ Physical domain } \\
\hline & $B$ & $S E B$ & $\beta$ & $t$ & $P$ value \\
\hline Age & -0.037 & 0.115 & -0.019 & -0.321 & 0.749 \\
\hline Job status (current) & 0.644 & 0.298 & 0.122 & 2.164 & 0.032 \\
\hline Pain site (current) & -0.114 & 0.115 & -0.055 & -0.993 & 0.322 \\
\hline Current ADL & -0.421 & 0.152 & -0.168 & -2.766 & 0.006 \\
\hline Pain severity (last week) & -0.298 & 0.093 & -0.218 & -3.208 & 0.002 \\
\hline Sleep duration & 0.173 & 0.064 & 0.159 & 2.711 & 0.007 \\
\hline Effect of therapy & -0.265 & 0.135 & -0.122 & -1.966 & 0.049 \\
\hline Suicidal ideation & 1.223 & 0.348 & 0.203 & 3.512 & 0.001 \\
\hline
\end{tabular}

ADL: activities of daily living, SE: standard error.

Table 8. Multiple linear regression analysis for psychological domain $(n=251)$

\begin{tabular}{|c|c|c|c|c|c|}
\hline \multirow{2}{*}{ Variable } & \multicolumn{5}{|c|}{ Psychological domain } \\
\hline & $B$ & $S E B$ & $\beta$ & $t$ & $P$ value \\
\hline Sex & -0.074 & 0.340 & -0.012 & -0.218 & 0.828 \\
\hline Age & -0.226 & -0.138 & -0.095 & -1.642 & 0.102 \\
\hline Job status (current) & 1.029 & 0.382 & 0.162 & 2.697 & 0.008 \\
\hline Current ADL & -0.320 & 0.189 & -0.105 & -1.690 & 0.092 \\
\hline Pain severity (last week) & -0.201 & 0.113 & -0.125 & -1.783 & 0.076 \\
\hline Sleep duration & 0.168 & 0.079 & 0.128 & 2.137 & 0.034 \\
\hline Effect of therapy & -0.209 & 0.167 & -0.081 & -1.250 & 0.213 \\
\hline Suicidal ideation & 2.264 & 0.418 & 0.319 & 5.422 & $<0.001$ \\
\hline
\end{tabular}

ADL: activities of daily living, SE: standard error.

Table 9 shows the multiple linear regression between the social domain and the patient's status (items in Table 1 and Table 2). The correlation between items in Table 4 and social domain was established through a multiple linear regression analysis. Among them, items that were correlated with a $P$ value $<0.05$ were sex $(\mathrm{t}=2.276, P=0.024)$, current job status $(\mathrm{t}=2.06, P=0.041)$, current ADL $(\mathrm{t}=$
$-3.377, P=0.001)$, and suicidal ideation $(\mathrm{t}=2.847, P=0.005)$.

Table 10 shows the multiple linear regression between the environment domain and the patient's status (items in Table 1 and Table 2). The correlation between the items in Table 4 and the environment domain was a multiplelinear regression. Among them, items that were correlated with a $P$ value $<0.05$ were age $(\mathrm{t}=-2.163, P=0.032)$, current 
Table 9. Multiple linear regression analysis for social domain $(n=251)$

\begin{tabular}{|c|c|c|c|c|c|}
\hline \multirow{2}{*}{ Variable } & \multicolumn{5}{|c|}{ Social domain } \\
\hline & $B$ & $S E B$ & $\beta$ & $t$ & $P$ value \\
\hline Sex & 1.031 & 0.453 & 0.139 & 2.276 & 0.024 \\
\hline Age & -0.265 & 0.181 & -0.091 & -1.460 & 0.146 \\
\hline Job status (current) & 1.033 & 0.502 & 0.131 & 2.060 & 0.041 \\
\hline Current ADL & -0.874 & 0.259 & -0.224 & -3.377 & 0.001 \\
\hline Pain severity (last week) & -0.224 & 0.152 & -0.112 & -1.471 & 0.143 \\
\hline Sleep duration & 0.176 & 0.101 & 0.109 & 1.737 & 0.084 \\
\hline Effect of therapy & -0.098 & 0.225 & -0.031 & -0.436 & 0.663 \\
\hline Suicidal ideation & 1.643 & 0.577 & 0.186 & 2.847 & 0.005 \\
\hline
\end{tabular}

ADL: activities of daily living, SE: standard error.

Table 10. Multiple linear regression analysis for environment domain $(n=251)$

\begin{tabular}{|c|c|c|c|c|c|}
\hline \multirow{2}{*}{ Variable } & \multicolumn{5}{|c|}{ Environment domain } \\
\hline & $B$ & SE B & $\beta$ & $t$ & $P$ value \\
\hline Age & -0.269 & 0.124 & -0.131 & -2.163 & 0.032 \\
\hline Job status (current) & 0.840 & 0.331 & 0.152 & 2.539 & 0.012 \\
\hline Pain site (current) & -0.149 & 0.127 & -0.068 & -1.173 & 0.242 \\
\hline Current ADL & -0.489 & 0.175 & -0.182 & -2.802 & 0.006 \\
\hline Pain severity (last week) & -0.129 & 0.100 & -0.093 & -1.294 & 0.197 \\
\hline Sleep duration & 0.233 & 0.067 & 0.211 & 3.451 & 0.001 \\
\hline Effect of therapy & -0.355 & 0.144 & -0.160 & -2.453 & 0.015 \\
\hline Suicidal ideation & 0.714 & 0.374 & 0.116 & 1.907 & 0.058 \\
\hline
\end{tabular}

ADL: activities of daily living, SE: standard error.

job status $(\mathrm{t}=2.539, P=0.012)$, current ADL $(\mathrm{t}=-2.802, P=$ $0.006)$, sleep duration $(\mathrm{t}=3.451, P=0.001)$, and therapeutic effect $(\mathrm{t}=-2.453, P=0.015)$.

\section{DISCUSSION}

Through this survey, we wanted to determine the factors that influence CRPS patients. Since extreme pain is a major symptom of CRPS, the survey was prepared in anticipation of the possible problems caused by pain, such as ADL restrictions, sleep disorders, job maintenance, and economic difficulties. The WHOQOL-BREF scores for patients with CRPS are significantly lower than those for patients with other chronic diseases. Among the factors that show a connection with each domain, suicidal ideation has shown a high degree of association in all domains (BREFQ1, BREF-Q2, physical, psychological, social, and environmental).

CRPS patients were shown to have a high level of pain at an average score of $7.15 \pm 1.78$ (out of a total of 10 points) and showed higher pain levels compared to those in another study $(3.55 \pm 1.44,5.9 \pm 2.7)[14,15]$. As only $14.3 \%$ patients had an improvement in pain of more than $50 \%$, it turned out that there was not enough treatment. This could have been due to a combination of various factors; however, the fact that early diagnosis and treatment were not carried out is also important. Early diagnosis and treatment are known to play an important role in therapeutic outcomes [16-22]. The prolonged period of pain caused by delayed diagnosis changes the sensitivity of the peripheral and central nociceptive pathways. As a result, the intensity of pain can be increased by central sensitization [23]. This survey found that early diagnosis of the disease was not common. Only $140(56.5 \%)$ patients were diagnosed within one year, while $42(16.9 \%)$ patients were found to have taken more than 3 years to be diagnosed. In addition, the treatment period was also long. A total of 142 $(57.3 \%)$ patients were treated for more than three years, and $29(11.7 \%)$ of them were treated for more than 10 years.

For appropriate treatment of CRPS, pain control, recovery of function, psychological support, and patient education are important. Among these, patient education about the CRPS disease mechanism, diagnosis, and therapeutic treatment are believed to be the most important [17]. This helps in more effective treatment of CRPS. In this survey, 
the patients' knowledge of the disease was shown to be quite high. As many as $80 \%$ of patients said they knew about the pathophysiology and treatment of the disease. In addition, $70 \%$ of patients said they knew about the diagnosis.

Extreme pain, the most prominent characteristic of CRPS, can affect various parts of the body. Pain is the most important predictor of physical disability and limitation of the ADL $[24,25]$. Patients have limited activity due to muscle stricture, limited joint range of motion, and osteoporosis [26]. Physical restrictions can cause limitations on social functions and roles [27]. A total of $54.2 \%$ patients said that they could not perform their ADL without help. These limitations of functioning in daily life are known to affect health-related QOL [28]. In addition, limitations of daily activities lead to limitations in economic activities [29].

According to another study, only $31 \%$ of the patients were economically active [30]. In this survey, the unemployment rate was $57 \%$, and patients mentioned losing their jobs after the outbreak of CRPS. This number increased sharply from 7 (2.8\%) to 143 (57.0\%) after the CRPS outbreak; this is 15 times higher than the unemployment rate in Korea (Statistics Korea, September 2020). Restrictions on economic activities resulted in a decrease in household income, which also affected family members [29]. The minimum monthly wage in Korea (Minimum Wage Commission, Republic of Korea) is 1,795,310 won (1,620 USD, working for 40 hours a week). However, in this survey, $48.8 \%$ of the patients had a monthly wage (working 40 hours a week) of less than 1,000,000 won (902.4 USD). Additionally, $83.4 \%$ of the patients had financial difficulties.

Patients, on average, showed insufficient sleep time (4.92 \pm 2.28 hours). A total of $92.1 \%$ patients answered that they had insomnia due to pain; this was higher than the $80 \%$ found in other studies $[5,15]$. Compared to cases of other chronic pain diseases, such as fibromyalgia, they also had shorter sleep times $(6.37 \pm 1.82,6.37 \pm 1.93)[31,32]$. Insufficient sleep ( $<7$ hours) can cause obesity, diabetes, high blood pressure, coronary artery disease, and stroke [33-35]. It is known to affect the patient mentally, physically, and psychologically. Short sleep periods are also known to be associated with depression [36]. These sleep disorders are also known to affect QOL in patients with CRPS [15].

The survey results confirmed that pain in patients with CRPS is likely to be accompanied by psychological disorders such as depression and anxiety, which also affect the QOL of patients $[5,15]$. In addition, the rate of consumption of antipsychotics was $65.1 \%$ among the patients, which was higher than that in the study which reported $60 \%$ of CRPS patients experiencing stress events and psychologi- cal problems [5]. Surprisingly, the ratio of suicidal ideation among patients was found to be high, with its prevalence among $80.5 \%$ of the patients. Sharma et al. [37] reported that half of the patients with CRPS had suicidal ideation and $15 \%$ of them had attempted suicide.

The average score for each domain was as follows: 21.74 \pm 14.77 for physical, $25.22 \pm 17.66$ for psychological, $32.02 \pm$ 22.36 for social relationship, and $30.69 \pm 15.83$ for environmental (out of a total of 100 points each), less than half the score for dialysis patients (except environmental domain [53.17 \pm 15.59$]$ ), $51.23 \pm 18.61$ for psychological domain, $49.86 \pm 21.64$ for social domain, and $45.93 \pm 16.90$ for physical domain [38]. In addition, it was only half of the average score found in patients with traumatic brain injury [39]. This confirmed that the QOL of patients with CRPS was significantly lower and that they had lower satisfaction levels.

Many factors were thought to affect each domain. In particular, it was thought that the pain itself would greatly affect the QOL [11]. However, when the multiple linear regression analysis was performed by combining each factor that had a correlation, the correlation between suicidal ideation and current job was much higher than that of pain. In addition, the presence of therapeutic effect, sleep disturbance, and current ADL, although of different importance in each domain, served as a common link. Although the number of domains affected was small, pain score, age, and sex were found to be related. Correlation with QOL has not been found to be related to specific factors (social support, lesser soft tissue injury, pain site, delayed therapy, or diagnosis), which were associated with the already known prognosis [14,19,22,40-42].

Psychological problems, such as suicidal ideation, have been shown to be of high importance in correlation with QOL. It is thought to be the result of a combination of psychological problems (insomnia, anxiety) caused by low therapeutic effect and pain severity in patients and disorders of physical activity [43]. However, other study has reported the role of psychologic factors in poor prognosis were less important [42]. On the other hand, therapeutic effects have been shown to be important in both correlation and prognosis with QOL [42]. A younger age can be associated with better awareness of medical history, but the correlation of age with QOL has been shown to affect only the environmental domain [44].

Previous studies have already revealed the epidemiology and status of patients with CPRS $[6,11,14,19,43]$. However, the study on the QOL and epidemiology in patients with CRPS in South Korea was insufficient, which is why we conducted this survey. Differences from previous studies occurred in the epidemiology and status of patients with CRPS, especially in pain scores, sleep disorders, sui- 
cidal ideation, and knowledge of CRPS (pathophysiology, diagnosis, and therapy). This study has the advantage of having a variety of patients selected from multiple centers. However, it is characterized by the fact that most patients have chronic diseases and that the prevalence period is longer than that in other studies [37]. In particular, the high proportion of patients with intractable diseases and longer durations of diseases might be associated with a higher occurrence of suicidal ideation, sleep disorders, and pain severity than is observed in other studies. This is thought to work in the same context that patients have a higher understanding and knowledge of the disease but also have a lower treatment effect than is observed in other studies.

There are obvious limitations to the questionnaire, with 50 questions per patient and 26 of them for WHOQOLBREF; it is considered unsophisticated that the questions were not subdivided. Another limitation is that the survey was limited to patients at university hospitals. According to the higher pain score, higher sleep disorder, higher suicidal ideation, and more intractable patients, there might be a selection bias associated with severe patients in university hospitals in this study. However, in Korea, anyone can easily visit university hospitals and receive treatment. Therefore, it is thought that most patients with CRPS could be treated at university hospitals. The severe symptoms observed in this study may be associated with the strict and accurate diagnoses of university hospitals. In addition, this could be because the symptoms of Korean patients are worse than those in other studies.

In conclusion, most patients had moderate to severe pain (96.4\%), economic problems (83.4\%), limitations in ADL (98\%), sleep problems (92.2\%), and suicidal ideation (80.5\%), and consumed psychological medication (65.2\%). More than half of the patients (57\%) were unemployed after manifestation of CRPS symptoms. Many patients (72.1\%) were diagnosed more than six months after the symptoms occurred. The QOL of CRPS patients was generally low, especially in regards to occupation. ADL, sleep time, effect of therapy, and suicidal ideation were statistically correlated with multiple domains.

\section{CONFLICT OF INTEREST}

No potential conflict of interest relevant to this article was reported.

\section{FUNDING}

No funding to declare.

\section{ORCID}

Jaemoon Lee, https://orcid.org/0000-0001-5974-2955

Yun Hee Lim, https://orcid.org/0000-0003-2399-4768

Sung Jun Hong, https://orcid.org/0000-0002-2466-718X

Jae Hun Jeong, https://orcid.org/0000-0002-4341-572X

Hey Ran Choi, https://orcid.org/0000-0002-9899-0158

Sun Kyung Park, https://orcid.org/0000-0002-4133-5806

Jung Eun Kim, https://orcid.org/0000-0001-5125-3129

Eun Hi Park, https://orcid.org/0000-0002-3316-017X

Jae Hun Kim, https://orcid.org/0000-0002-6774-1829

\section{REFERENCES}

1. Maihöfner C, Seifert F, Markovic K. Complex regional pain syndromes: new pathophysiological concepts and therapies. Eur J Neurol 2010; 17: 649-60.

2. Chae WS, Kim SH, Cho SH, Lee JH, Lee MS. Reduction in mechanical allodynia in complex regional pain syndrome patients with ultrasound-guided pulsed radiofrequency treatment of the superficial peroneal nerve. Korean J Pain 2016; 29: 266-9.

3. Jeon SG, Choi EJ, Lee PB, Lee YJ, Kim MS, Seo JH, et al. Do severity score and skin temperature asymmetry correlate with the subjective pain score in the patients with complex regional pain syndrome? Korean J Pain 2014; 27: 339-44.

4. Shin NY, Kang DH, Jang JH, Park SY, Hwang JY, Kim SN, et al. Impaired recognition of social emotion in patients with complex regional pain syndrome. J Pain 2013; 14: 1304-9.

5. Marinus J, Van Hilten JJ. Clinical expression profiles of complex regional pain syndrome, fibromyalgia and a-specific repetitive strain injury: more common denominators than pain? Disabil Rehabil 2006; 28: 351-62.

6. Kim H, Lee CH, Kim SH, Kim YD. Epidemiology of complex regional pain syndrome in Korea: an electronic population health data study. PLoS One 2018; 13: e0198147.

7. Treede RD, Rief W, Barke A, Aziz Q, Bennett MI, Benoliel R, et al. A classification of chronic pain for ICD-11. Pain 2015; 156: 1003-7.

8. Fishman S, Ballantyne J, Rathmell JP, Bonica JJ. Bonica's management of pain. 4th ed. Baltimore, Lippincott, Williams \&Wilkins. 2010, pp xxxiii, 1661.

9. Harden RN, Oaklander AL, Burton AW, Perez RS, Richardson $\mathrm{K}$, Swan M, et al. Complex regional pain syndrome: practical diagnostic and treatment guidelines, 4 th edition. Pain Med 2013; 14: 180-229.

10. Rand SE, Basu S, Khalid S. Complex regional pain syndrome: current diagnostic and treatment considerations. Curr Sports Med Rep 2019; 18: 325-9.

11. Sohn HS, Lee DH, Lee KJ, Noh EC, Choi SH, Jang JH, et al. Impaired empathic abilities among patients with Complex 
Regional Pain Syndrome (Type I). Psychiatry Investig 2016; 13: 34-42.

12. Goebel A. Complex regional pain syndrome in adults. Rheumatology (Oxford) 2011; 50: 1739-50.

13. Bruehl S, Harden RN, Galer BS, Saltz S, Bertram M, Backonja $\mathrm{M}$, et al. External validation of IASP diagnostic criteria for Complex Regional Pain Syndrome and proposed research diagnostic criteria. International Association for the Study of Pain. Pain 1999; 81: 147-54.

14. Lee WJ, Jung CH, Hwang JY, Seong SJ, Han CH, Park JW, et al. Prognostic factors in complex regional pain syndrome type 1 occurring in the Korean army. Pain Med 2019; 20: 1989-96.

15. Galer BS, Henderson J, Perander J, Jensen MP. Course of symptoms and quality of life measurement in Complex Regional Pain Syndrome: a pilot survey. J Pain Symptom Manage 2000; 20: 286-92.

16. Birklein F, O'Neill D, Schlereth T. Complex regional pain syndrome: an optimistic perspective. Neurology 2015; 84: 89-96.

17. Grieve S, Llewellyn A, Jones L, Manns S, Glanville V, McCabe CS. Complex regional pain syndrome: an international survey of clinical practice. Eur J Pain 2019; 23: 1890-903.

18. Littlejohn G. Therapy: bisphosphonates for early complex regional pain syndrome. Nat Rev Rheumatol 2013; 9: 199-200.

19. Kang JE, Kim YC, Lee SC, Kim JH. Relationship between complex regional pain syndrome and working life: a Korean study. J Korean Med Sci 2012; 27: 929-33.

20. Li Z, Smith BP, Smith TL, Koman LA. Diagnosis and management of complex regional pain syndrome complicating upper extremity recovery. J Hand Ther 2005; 18: 270-6.

21. Ok SJ, Yang JY, Son JH, Jeong WJ, Lee YS, Kim WY, et al. Management of complex regional pain syndrome type 1 with total spinal block. Korean J Pain 2010; 23: 70-3.

22. Chen CK, Phui VE, Nizar AJ, Yeo SN. Percutaneous t2 and t3 radiofrequency sympathectomy for complex regional pain syndrome secondary to brachial plexus injury: a case series. Korean J Pain 2013; 26: 401-5.

23. Woolf CJ, Salter MW. Neuronal plasticity: increasing the gain in pain. Science 2000; 288: 1765-9.

24. Geertzen JH, Dijkstra PU, Groothoff JW, ten Duis HJ, Eisma WH. Reflex sympathetic dystrophy of the upper extremity--a 5.5-year follow-up. Part I. Impairments and perceived disability. Acta Orthop Scand Suppl 1998; 279: 12-8.

25. Vaneker M, Wilder-Smith OH, Schrombges P, Oerlemans HM. Impairments as measured by ISS do not greatly change between one and eight years after CRPS 1 diagnosis. Eur J Pain 2006; 10: 639-44.

26. Miller MH, Topliss DJ. Chronic upper limb pain syndrome (repetitive strain injury) in the Australian workforce: a systematic cross sectional rheumatological study of 229 patients. J Rheumatol 1988; 15: 1705-12.

27. Savaş S, Baloğlu HH, Ay G, Cerçi SS. The effect of sequel symptoms and signs of Complex Regional Pain Syndrome type 1 on upper extremity disability and quality of life. Rheumatol Int 2009; 29: 545-50.

28. Kemler MA, de Vet HC. Health-related quality of life in chronic refractory reflex sympathetic dystrophy (complex regional pain syndrome type I). J Pain Symptom Manage 2000; 20: 68-76.

29. Kemler MA, Furnée CA. The impact of chronic pain on life in the household. J Pain Symptom Manage 2002; 23: 433-41.

30. DeGood DE, Cundiff GW, Adams LE, Shutty MS Jr. A psychosocial and behavioral comparison of reflex sympathetic dystrophy, low back pain, and headache patients. Pain 1993; 54: 317-22.

31. Theadom A, Cropley M, Humphrey KL. Exploring the role of sleep and coping in quality of life in fibromyalgia. J Psychosom Res 2007; 62: 145-51.

32. Kothari DJ, Davis MC, Yeung EW, Tennen HA. Positive affect and pain: mediators of the within-day relation linking sleep quality to activity interference in fibromyalgia. Pain 2015; 156: 540-6.

33. Grandner MA, Chakravorty S, Perlis ML, Oliver L, Gurubhagavatula I. Habitual sleep duration associated with selfreported and objectively determined cardiometabolic risk factors. Sleep Med 2014; 15: 42-50.

34. Liu Y, Wheaton AG, Chapman DP, Croft JB. Sleep duration and chronic diseases among U.S. adults age 45 years and older: evidence from the 2010 Behavioral Risk Factor Surveillance System. Sleep 2013; 36: 1421-7.

35. Gallicchio L, Kalesan B. Sleep duration and mortality: a systematic review and meta-analysis. J Sleep Res 2009; 18: 14858.

36. Zhai L, Zhang H, Zhang D. Sleep duration and depression among adults: a meta-analysis of prospective studies. Depress Anxiety 2015; 32: 664-70.

37. Sharma A, Agarwal S, Broatch J, Raja SN. A web-based crosssectional epidemiological survey of complex regional pain syndrome. Reg Anesth Pain Med 2009; 34: 110-5.

38. Sathvik BS, Parthasarathi G, Narahari MG, Gurudev KC. An assessment of the quality of life in hemodialysis patients using the WHOQOL-BREF questionnaire. Indian J Nephrol 2008; 18: 141-9.

39. Chiu WT, Huang SJ, Hwang HF, Tsauo JY, Chen CF, Tsai SH, et al. Use of the WHOQOL-BREF for evaluating persons with traumatic brain injury. J Neurotrauma 2006; 23: 1609-20.

40. Feldman SI, Downey G, Schaffer-Neitz R. Pain, negative mood, and perceived support in chronic pain patients: a daily diary study of people with reflex sympathetic dystrophy syndrome. J Consult Clin Psychol 1999; 67: 776-85.

41. Sandroni P, Benrud-Larson LM, McClelland RL, Low PA. Complex regional pain syndrome type I: incidence and prevalence in Olmsted county, a population-based study. Pain 2003; 103: 199-207. 
42. Brunner F, Nauer M, Bachmann LM. Poor prognostic factors in complex regional pain syndrome 1: a Delphi survey. J Rehabil Med 2011; 43: 783-6.

43. Lee DH, Noh EC, Kim YC, Hwang JY, Kim SN, Jang JH, et al. Risk factors for suicidal ideation among patients with complex regional pain syndrome. Psychiatry Investig 2014; 11:
$32-8$.

44. Lee SJ, Yoo YM, You JA, Shin SW, Kim TK, Abdi S, et al. Successful removal of permanent spinal cord stimulators in patients with complex regional pain syndrome after complete relief of pain. Korean J Pain 2019; 32: 47-50. 